\title{
STRATEGI PENGEMBANGAN URBAN HERITAGE TOURISM KOTA CIREBON, JAWA BARAT
}

\author{
Theresia Budi Jayanti \\ Jurusan Arsitektur Fakultas Teknik Universitas Tarumanagara \\ Jl. Letjen S. Parman No. 1 Jakarta Barat \\ *Email: theresia.bj@gmail.com
}

\begin{abstract}
Tourism potential of a city can be developed through the city's historical heritage. The history of Cirebon began around the 15th century, a small village in the Java Sea Coast named Muara Jati and its develop into the kingdom with a King named Walangsungsang (Cakrabumi). In the years 1529-1945, the Kingdom of Cirebon developed into four (4) Royal Palaces, namely: Karatons Kasepuhan, Royal Palaces Kanoman, Royal Palaces Kacirebonan and the Royal Palaces Kaprabonan. It's cause Cirebon City has potential historical sights. Seeing the potential access of existing and historical value, Cirebon City tourism can be developed through the concept of urban heritage tourism. This study aims to discover the potential and strategies for developing the urban heritage tourism concept in Cirebon City. The research method used descriptive qualitative approach. Primary data obtained by field observations and documentation. Secondary data were obtained through, journals, books and the Internet data that is relevant. Then analysis of urban heritage tourism development strategy through a SWOT analysis. The findings are: access, historic building, cultural daily life, community and government is crucial in the development of urban heritage tourism Cirebon City.
\end{abstract}

Keywords: stategy, urban heritage tourism, Cirebon.

\section{PENDAHULUAN}

Dalam perkembangan perekonomian di Indonesia, sektor pariwisata merupakan salah satu faktor penting. Era globalisasi sekarang ini, pembangunan dunia pariwisata dapat dijadikan prioritas dalam menunjang pembangunan suatu daerah di Indonesia. Pembangunan kepariwisataan bisa dengan memanfaatkan daya tarik wisata baik berupa seni budaya, kehidupan masyarakat, keanekaragaman flora fauna, benda purbakala atau peninggalan sejarah serta keindahan alamnya. Pengembangan pariwisata ini dilakukan untuk mengenalkan potensi daerah kepada wisatawan baik domestik atau mancanegara, sehingga khususnya dapat meningkatkan pendapatan masyarakat daerah tersebut dan menambah devisa negara pada umumnya. Tujuan pengembangan pariwisata tersebut tentu saja akan berhasil jika didukung oleh akomodasi, aksesibiltas, sumber daya manusia, kesadaran masyarakatnya serta objek wisata daerah itu sendiri baik dari alam atau buatan manusia. Objek dan daya tarik wisata adalah segala sesuatu baik berupa bentukan dan/atau aktivitas dan fasilitas yang saling berhubungan dan memiliki daya tarik tersendiri sehingga dapat menarik minatwisatawan atau pengunjung untuk mengunjungi suatu daerah atau tempat tertentu. Objek dan daya tarik wisata tersebut harus memiliki tiga komponen utama sebagai produk untuk dijual di pasar wisata, yaitu: aktraksi, fasilitas dan aksesibilitas (Hadinoto,1996, dalam Widiyati, 2015).

Indonesia sebagai negara yang mempunyai potensi wisata yang besar, sudah mulai berbenah dan mengembangkan sektor pariwisata. Program-program pembangunan pariwisata di Indonesia yang meliputi pembenahan pengembangan obyek wisata dan faktor pendukung wisata lainnya bisa dikatakan memiliki kemajuan. Selain hal tersebut, melalui slogan atau jargon pariwisata Indonesia yang baru (sebelumnya adalah Visit Indonesia) yaitu 'Wonderfull Indonesia' atau 'Pesona Indonesia' diharapkan Indonesia menjadi idaman masyarakat penjuru dunia untuk datang kesini. Slogan atau jargon tidak hanya di skala negara, tetapi skala propinsi ataupun kota juga sudah ada, diantaranya Enjoy Jakarta, Semarang- 
Variety of Culture, Sparkling Surabaya, Bandung-Everlasting Beauty, Banyuwangi-The Sunrise of Java, Solo-The Spirit of Java, JogjaNever Ending Asia, Pekalongan-World's City of Batik. Slogan atau jargon tersebut merupakan salah satu upaya pemerintah pusat dan daerah dalam mengembangkan sektor pariwisata. Hasil yang telah dicapai dapat diukur dengan adanya peningkatan jumlah wisatawan, penerimaan devisa negara serta pendapatan daerah, meskipun masih banyak potensi daerah lain di Indonesia yang belum dan masih bisa ditingkatkan di sektor wisata.

Sebagai negara kepulauan terbesar di dunia, Indonesia tentu saja memiliki potensi wisata yang sangat beranekaragam baik berupa objek wisata alam ataupun budaya masyarakatnya. Sejarah panjang Indonesia juga tidak bisa terlepas dari jaman adanya kerajaankerajaan, jaman penjajahan sampai dengan jaman reformasi sekarang ini yang tentu saja memberikan suatu peninggalan sejarahnya, baik berupa bangunan, benda-benda, maupun culture masyarakat daerah itu sendiri. Pemerintah mengatur tentang pemanfaatan peninggalan bangunan dan benda cagar budaya melalui UU Nomor 11 tahun 2010 tentang Cagar Budaya.

Keberadaan dan pemanfaatan bangunan bersejarah, situs atau benda cagar budaya dengan baik dapat mengangkat karakteristik budaya daerah serta mengembangkan potensi heritage tourism atau wisata warisan budaya. Pederson (2002, dalam Southall dan Robinson,2011): "heritage tourism as embracing both eco tourism and cultural tourism, with an emphasis on conservation and cultural heritage". Melalui definisi tersebut dijelaskan bahwa wisata warisan budaya dapat merangkul ekowisata dan wisata budaya pada saat bersamaan dan menitikberatkan kepada konservasi dan warisan budaya itu sendiri. Pengembangan wisata warisan budaya di perkotaan sangat ideal dilaksanakan karena suatu kota tidak akan kehilangan identitas lokal, serta memberikan pemahaman dan rasa kebanggaan terhadap sejarah kota dan kebudayaan lokal masyarakat setempat (Widayanti, 2015).

Kota Cirebon merupakan salah satu kota di Jawa Barat yang terletak pada lokasi stategis dan menjadi simpul pergerakan transportasi antara Jawa Barat dengan Jawa Tengah melalui Jalur Pantura. Sejarah berdirinya kota Cirebon bermula sekitar abad 15 dengan sebuah desa kecil di Pantai Laut Jawa bernama Muara Jati dan dalam perkembangannya berubah menjadi Kerajaan Cirebon dengan raja Pangeran Walangsungsang yang bergelar Cakrabumi. Pada tahun 1529-1945, Kerajaan Cirebon berkembang menjadi 4 (empat) Keraton, yaitu: Keraton Kasepuhan, Keraton Kanoman, Keraton Kacirebonan dan Keraton Kaprabonan. Ragam perkembangan inilah yang menyebabkan Kota Cirebon mempunyai potensi wisata sejarah yang menarik. Melihat potensi akses dan nilai historis yang ada, pariwisata Kota Cirebon bisa dikembangkan menjadi urban heritage tourism yang mengutamakan wisata sejarah dan budaya.

\section{METODE PENELITIAN}

Penelitian ini berlokasi di Kota Cirebon, Jawa Barat. Tujuan dari penelitian ini adalah untuk menemukan potensi dan strategi pengembangan urban heritage tourism di Kota Cirebon. Metode penelitian menggunakan pendekatan kualitatif deskriptif. Metode kualitatif digunakan untuk mengidentifikasi faktor internal dan eksternal Kota Cirebon. Pengumpulan data yang digunakan melalui data primer dan sekunder. Data primer diperoleh dengan cara observasi lapangan dan dokumentasi. Data sekunder diperoleh melalui, jurnal, buku dan data internet yang relevan. Setelah data primer dan data sekunder terkumpul, kemudian dilakukan analisa strategi pengembanganurban heritage tourism melalui analisis SWOT. Hasil temuan penelitian adalah kemudahan akses, tempat bersejarah yang ada, budaya keseharian penduduk, peran serta masyarakat dan pemerintah merupakan hal yang penting dalam mengembangkan urban heritage tourism Kota Cirebon.

\section{HASIL DAN PEMBAHASAN}

Potensi wisata adalah semua objek (baik berupa alam, budaya, buatan) yang memerlukan penanganan yang baik agar dapat memberikan nilai daya tarik bagi wisatawan (Damanik dan Weber, 2006). Untuk meningkatkan potensi heritage tourism di Kota Cirebon, terdapat beberapa kriteria yang dapat diidentifikasi, yaitu: 


\section{Kondisi Umum Kota Cirebon}

\section{Aksesibilitas dan fasilitas}

Kota Cirebon merupakan salah satu kota di Jawa Barat yang terletak pada lokasi stategis dan menjadi simpul pergerakan transportasi antara Jawa Barat dengan Jawa Tengah. Ada beragam pilihan moda transportasi umum jalur darat menuju Cirebon, misalnya: bus, mobil travel, maupun kereta api. Jika menggunakan transportasi udara, maka rute penerbangan yang dipilih adalah Jakarta atau Bandung, kemudian perjalanan dilanjutkan dengan transportasi darat. Untuk transportasi dalam kota selain dengan transportasi pribadi/menyewa kendaraan rental, wisatawan bisa menggunakan becak, ojek, taksi maupun angkutan umum. Transportasi becak dan angkutan umum sangat mudah ditemukan di Cirebon, hanya saja untuk angkutan umum rutenya masih belum terkoneksi secara maksimal; khususnya mengunjungi tempattempat wisata. Sangat diharapkan adanya transportasi khusus wisata yang menghubungkan tempat-tempat wisata di Cirebon seperti apa yang sudah dilakukan Pemerintah Kota Jakarta dan Bandung.

Tingkat perkembangan daerah sebagai pusat pertumbuhan tidak bisa terlepas dari fasilitas pendukung lainnya. Keberadaan tempat penginapan, pasar dan pusat perbelanjaan termasuk penentu terhadap aktivitas wisata di di kota tersebut. Pariwisata di Kota Cirebon juga ditunjang oleh ketersediaan fasilitas penginapan, baik kelas berbintang maupun kelas homestay. Disamping itu, juga terdapat beberapa pasar tradisional, pasar sekaten (hanya saat Syawal), dan juga mall seperti Grage Mall, Cirebon Superblok Mall dan Grage City Mall.

\section{Bangunan Bersejarah}

Kota Cirebon memiliki potensi wisata budaya yang cukup besar, baik berupa wisata alam maupun wisata buatan. Perkembangan kebudayaan Cirebon tidak bisa terlepas dari latar belakang sejarahnya. Sejarah berdirinya kota Cirebon bermula sekitar abad 15 dengan sebuah desa kecil di Pantai Laut Jawa bernama Muara Jati dan dalam perkembangannya berubah menjadi Kerajaan Cirebon yang kemudian berkembang lagi menjadi 4 Keraton (tahun 1529-1945). Berdirinya Kerajaan Cirebon menandai awal Kerjaaan Islam di Cirebon. Penggunaan pagar keliling dari pasangan batu bata menunjukkan adanya pengaruh budaya Jawa pada bangunan Keraton.
Bangunan Keraton peninggalan Kerajaan Cirebon dan bangunan kuno lainnya merupakan salah satu potensi wisata budaya Kota Cirebon; diantaranya:

1. Keraton Kasepuhan (tahun 1529)

Keraton Kasepuhan terletak di Kelurahan Kasepuhan yang termasuk dalam zona perdagangan (Gambar 1). Keraton Kasepuhan berdiri di tahun 1529 oleh Pangeran Mas Mochammad Arifin (cicit Sunan Gunung Jati) dan merupakan peninggalan sejarah Kerajaan Islam yang merupakan pusat pemerintahan masa lalu. Keberadaan Keraton Kasepuhan juga menunjukkan bahwa terjadi akulturasi di Kota Cirebon. Akulturasi yang terjadi tidak hanya antara masyarakat Sunda dan Jawa, tetapi juga Cina, India, Arab dan Eropa. Bukti akulturasi yang bisa dilihat adalah gerbang yang menyerupai pura di Bali; ukiran daun pintu gapura yang bergaya Eropa; tembok bata merah yang mengelilingi Keraton menunjukkan khas arsitektur Jawa; serta adanya keramik Cina di dinding dan pagar Siti Hinggilnya (Gambar 2). Bangunan keraton yang menghadap ke utara dengan pasar di sebelah timur, Masjid di sebelah barat dan ditengahnya terdapat alun-alun; merupakan ciri tata letak keraton didaerah pesisir.

Keraton Kasepuhan mempunyai area utama yang berisikan bangunan induk keraton serta bangunan penunjang lainnya, antara area utama keraton dengan area Tajug Agung (masjid) dibatasi tembok. Di dalam area utama keraton ini terdapat beberapa bangunan di antaranya: Taman Dewandaru, Museum Benda Kuno, Museum Kereta, Lunjuk, Sri Manganti, Bangunan Induk Keraton. Museum yang ada di Keraton ini digunakan sebagai tempat penyimpanan banda-benda pusaka atau benda peninggalan sejarah serta kereta-kereta kerajaan, misalnya Kereta Singo Barong. Pada Bangunan induk keraton, kegiatan kesultanan dilakukan disini oleh Sultan. Pada bangunan induk ini terdapat beberapa ruangan dengan fungsi yang berbeda, di antarannya: Kutagara Wadasan, Kuncung, Jinem Pangrawit, Bangsal Pringgandani, Bangsal Prabayasa, Bangsal Agung Panembahan, Kaputran, dapur (Gambar 3 dan 4). 


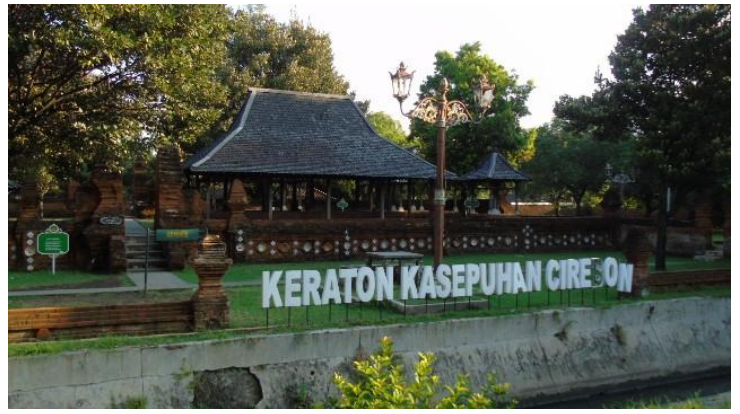

Gambar 1. Keraton Kasepuhan Cirebon Sumber: www. http://lalerijo.com

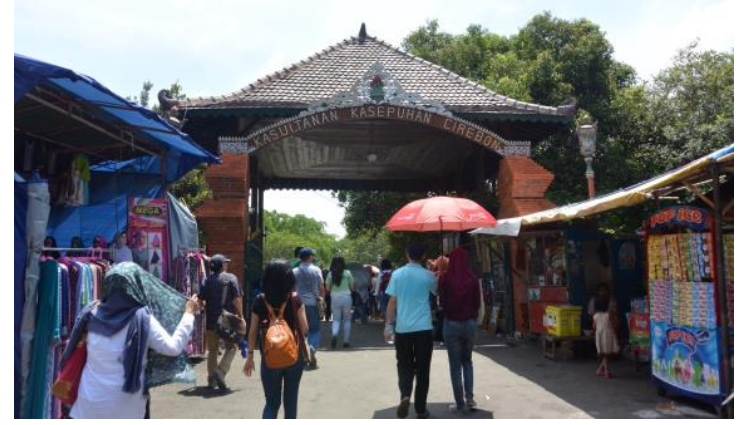

Gambar 2. Pintu Gerbang Keraton Kasepuhan Cirebon, ketika ada atraksi Pasar Rakyat

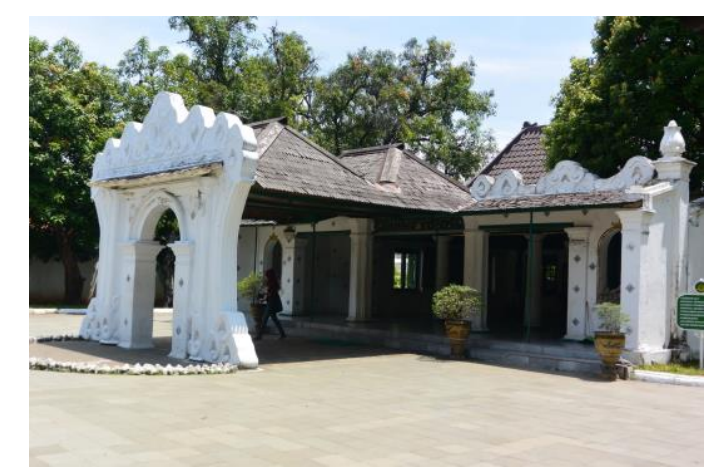

Gambar 3. Siti Hinggil Keraton Kasepuhan Cirebon

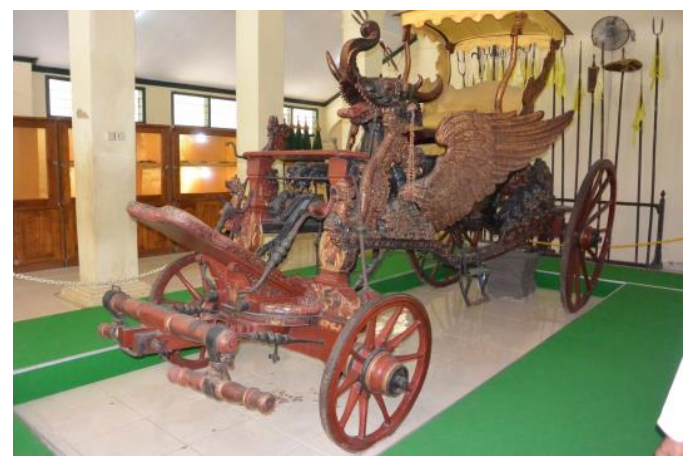

Gambar 4. Kereta Singo Barong Keraton Kasepuhan Cirebon

2. Keraton Kanoman

Kerajaan Cirebon dibagi menjadi Keraton Kanoman dan Keraton Kasepuhan, sehingga ciri-ciri khas kedua keraton ini tidak jauh berbeda. Keraton Kanoman didirikan sekitar tahun 1588 oleh Pangeran Kertawijaya yang bergelar Sultan Anom I (Gambar 5). Letak Keraton ini berada di Kelurahan Pulasaren Kecamatan Pekalipan dan termasuk dalam zona Perdagangan, atau 300 meter seberlah utara Keraton Kasepuhan. Keraton Kanoman memiliki atraksi budaya yang sama dengan Keraton Kasepuhan. Kondisi bangunan Keraton ini masih cukup baik. Salah satu bangunan penting yang terdapat pada komplek Keraton Kanoman adalah Winata. Sama halnya dengan Keraton Kasepuhan, Keraton Kanoman juga memiliki alun-alun, masjid, Siti Hinggil dan Langgar Kraton. Jika pada Kraton Kasepuhan bangunan didominasi bata merah, sedangkan pada Kraton Kanoman bangunan didominasi warna putih, kecuali pada masjid agung dan bangsal kraton. Namun ciri khas bangunan Cirebon masih dapat terlihat dari tempelantempelan piring keramik Cina/Eropa pada dinding bangunan (Gambar 6).

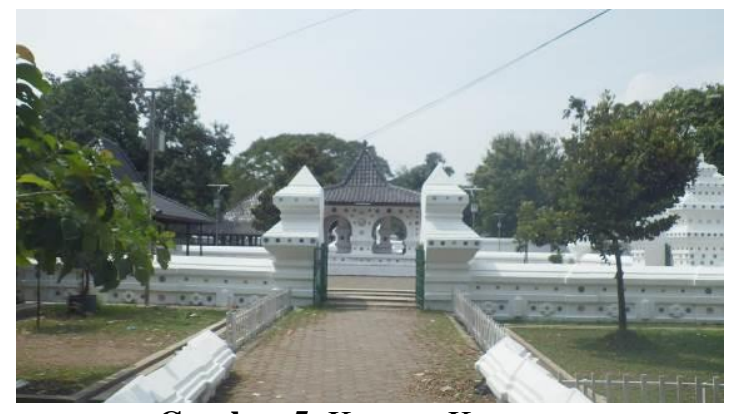

Gambar 5. Keraton Kanoman

Sumber: www. arifh80.files.wordpress.com

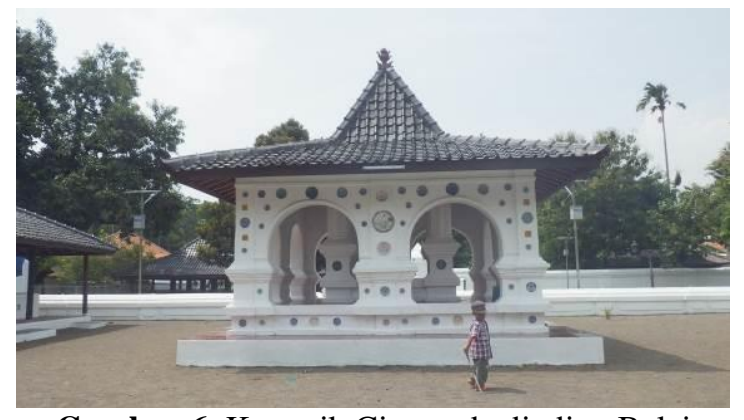

Gambar 6. Keramik Cina pada dinding Balai Manguntur Keraton Kanoman

Sumber: www. arifh80.files.wordpress.com

\section{Keraton Kacirebonan}

Letak Keraton Kacirebonan berada di Kelurahan Jagasatru Kecamatan Pakalipan dan termasuk dalam Zona Perdagangan sehingga lokasinya dekat dengan Pusat Pelayanan atau sekitar $1 \mathrm{~km}$ barat daya 
Keraton Kasepuhan (Gambar 7). Keraton Kacirebonan merupakan pecahan dari Keraton Kanoman, karena politik Belanda. Keraton ini didirikan pada tahun 1808 oleh Pangeran Muhammad Haerudhin. Pada komplek Keraton Kacirebonan terdapat beberapa bangunan penting yaitu bangunan induk Keraton, Paseban, Langgar, Gedong Ijo, Pringgowati, Kaputren dan Tajug (mushola). Bangunan induk Keraton saat ini digunakan sebagai tempat tinggal sehari-hari Sultan beserta keluarganya. Bangunan ini juga terdiri dari beberapa ruangan seperti ruang kerja Sultan, pecira, prabayasa, dapur dan teras. Terdapat 2 Paseban di komplek keraton, yaitu di barat dan timur keraton. Paseban ditopang oleh 8 buah tiang dan 4 saka guru dengan atap joglo. Tajug (mushola) berada di sebelah barat bangunan induk; diantara tajug dan paseban terdapat dinding pemisah, tetapi ada pintu penghubung di sisi barat tembok (Gambar 8).

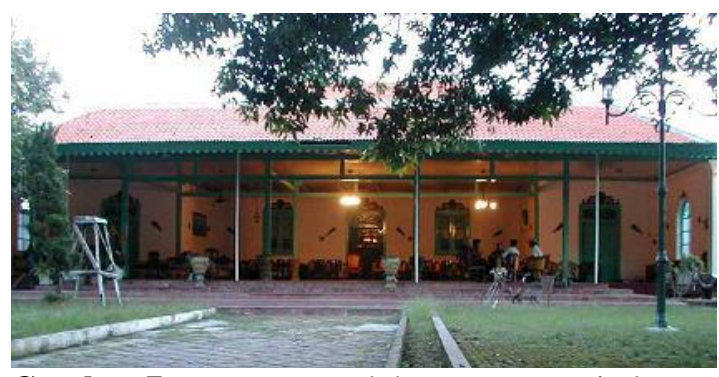

Gambar 7. Bangunan Induk Keraton Kacirebonan Sumber: http://www.disparbud.jabarprov.go.id

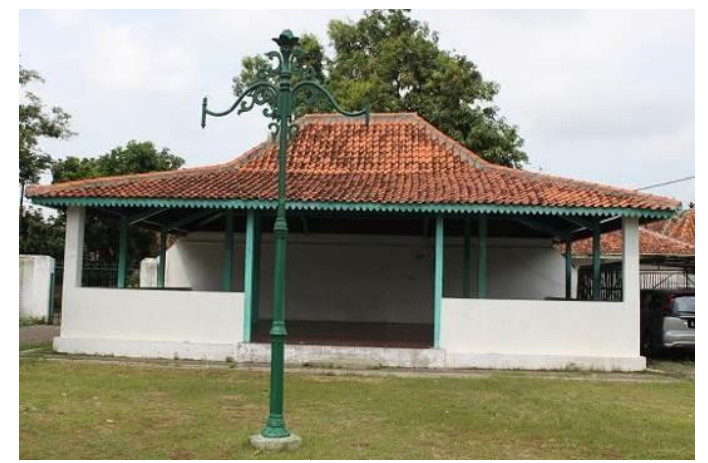

Gambar 8. Paseban Keraton Kacirebonan Sumber: http://www.disparbud.jabarprov.go.id

4. Keraton Kaprabonan

Keraton Kaprabonan terletak di Kelurahan Lemah Wungkuk di zona perdagangan sehingga dekat dengan pusat Pelayanan (Gambar 9). Keraton ini juga merupakan hasil paembagian dari Keraton Kanoman.
Tidak ada atraksi yang ditampilkan di Keraton ini karena saat ini digunakan sebagai tempat tinggal kerabat Keraton.

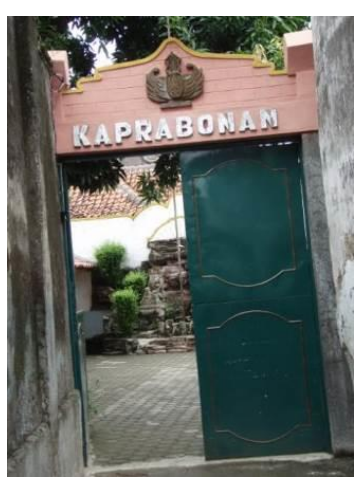

Gambar 9. Pintu Gerbang Keraton Kaprabonan Sumber: http://jurnalpatrolinews.com

5. Masjid Sang Cipta Rasa Kasepuhan Terletak di Kelurahan Kasepuhan Kecamatan Lemah Wungkuk dan termasuk dalam zona perdagangan (Gambar 10). Masjid ini merupakan peninggalan Walisanga yang dibangun pada tahun 1498 di komplek Keraton Kasepuhan. Keunikan dari masjid ini adalah tidak memiliki Menara Masjid dan bengunannya memiliki gaya arsitektur tersendiri. Masjid dibangun oleh arsitek Majapahit waktu itu yaitu Raden Sepat. Bangunan utama/asli Masjid Agung Sang Cipta Rasa memiliki sembilan pintu yang merupakan simbol dari Sembilan Wali (Walisongo). Selain itu, masjid ini memiliki 12 sokoguru yang terbuat dari kayu Jati dengan diameter sekitar $60 \mathrm{~cm}$ dan tinggi yang mencapai 14 meter. Keunikan lain dari masjid ini adalah memiliki dua Maksurah dan dua Mimbar; yang satu digunakan oleh Sultan atau Keluarga Keraton Kasepuhan, sedangkan yang satunya lagi digunakan oleh Sultan atau Keluarga Keraton Kanoman.

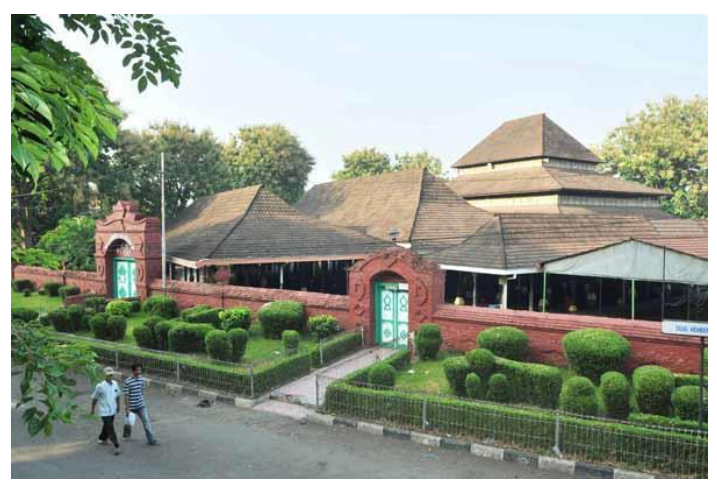

Gambar 10. Masjid Sang Cipta Rasa Kasepuhan Sumber: http://intisari-online.com/Travelling/Travel 
Kondisi bangunan masjid saat ini cukup baik, meskipun sudah mengalami revitalisasi, misalnya sokoguru. Fasilitas yang dimiliki dan atraksi yang ada adalah sebagaimana layaknya sebuah masjid sebagai kegiatan sehari-hari (Gambar 11).
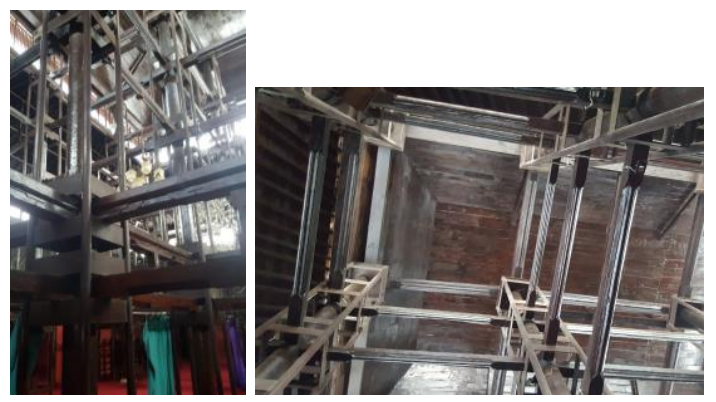

Gambar 11. Kondisi Soko Guru dan Atap yang Direvitalisasi

\section{Masjid Merah Panjunan}

Masjid ini didirikan oleh Syarif Abdurrahman atau Pangeran Panjunan, seorang keturunan Arab yang memimpin sekelompok imigran dari Baghdad, dan kemudian menjadi murid Sunan Gunung Jati (Gambar 12). Masjid Merah Panjunan berlokasi di Kampung Panjunan yang terdapat banyak pengrajin keramik dan termasuk dalam zona perdagangan. Umur masjid ini sama dengan Masjid Sang Cipta Rasa Kasepuhan. Gaya arsitektur juga sama dengan Masjid Sang Cipta Rasa Kasepuhan, hanya saja ukurannya lebih kecil.

Bagian depan masjid merupakan pintu masuk berupa gapura yang terbuat dari susunan bata merah. Bentuk gapuranya menunjukkan pengaruh Hindu dari jaman Majapahit yang banyak bertebaran di daerah Cirebon. Pada bagian dalam, umpak pada tiang penyangga memperlihatkan pengaruh kebudayaan Jawa. Sementara keramik yang menempel pada dinding memperlihatkan pengaruh budaya Cina.

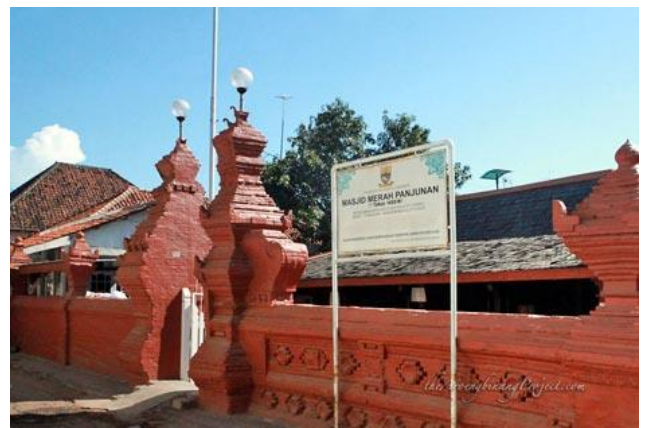

Gambar 12. Gapura Depan Masjid Merah Panjunan Sumber: http://www.thearoengbinangproject.com

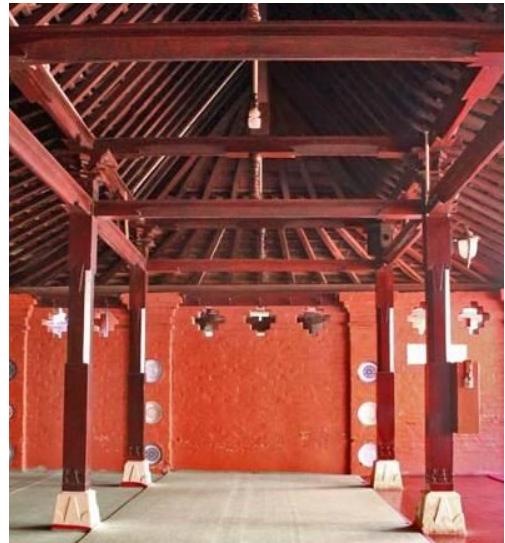

Gambar 13. Bagian Dalam Masjid Merah Panjunan Sumber: http://www.thearoengbinangproject.com

7. Kabuyutan Trusmi

Kabuyutan Trusmi terletak di Plered, Cirebon; merupakan situs bersejarah peninggalan kebudayaan Islam Jawa dan juga merupakan komplek pemakaman yang terdiri dari beberapa bangunan yang memiliki fungsi masing-masing (Gambar 14). Kabuyutan Trusmi didirikan oleh $\mathrm{Ki}$ Buyut yang merupakan putra pertama Parbu Siliwangi (Pangeran Walangsungsang atau Pangeran Cakrabuana), yang merupakan pendidri kerajaan Cirebon. Komplek Kabuyutan ini dikelilingi oleh tembok bata merah dan didalamnya terdapat beberapa bangunan yang mempunyai fungsi masingmasing, diantaranya: bale pakuncen, pendopo, bale paseban, masjid, tempat wudhu, ruang peziarah, jinem kulon, jinem wetan, bale pesalinan, pawestren, pewadonan, pakulahan dan gerbang kori agung. Bangunan yang ada di komplek Kabuyutan ini sebagian besar memiliki pintu yang rendah, sehingga orang yang lewat harus membungkuk. Hal ini sesuai dengan budaya masyarakat Jawa pada umumnya bahwa kita harus hormat kepada orang yang lebih tua sekaligus menunjukkan rasa hormat terhadap pemilik rumah (Gambar 15 dan 16).

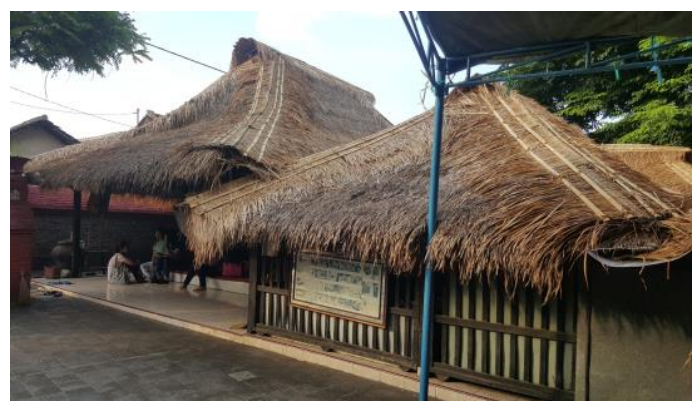

Gambar 14. Bagunan di Kabuyutan Trusmi 


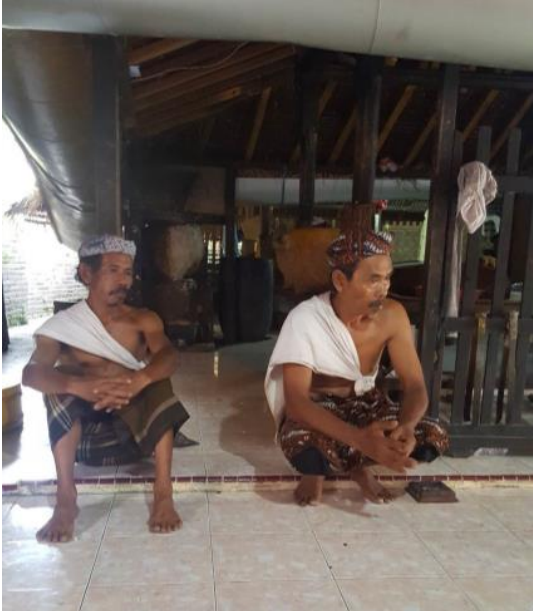

Gambar 15. Budaya berpakaian di Kabuyutan Trusmi

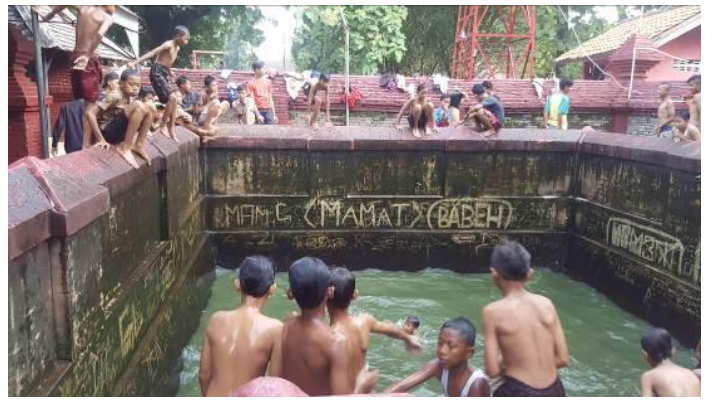

Gambar 16. Atraksi Di Kabuyutan Trusmi

8. Taman Air Gua Sunyaragi

Terletak $6 \mathrm{~km}$ dari pusat pelayanan yaitu di Kelurahan Sunyaragi Kecamatan Kesambi yang termasuk dalam zona Pendidikan dan Olahraga. Taman air Gua Sunyaragi memiliki gaya arsitektur Purba dan merupakan tempat melakukan meditasi dari para Sultan di masa lalu. Fasilitas penunjang di sekitar lokasi sudah cukup baik dengan tersedianya toilet umum, tempat parkir, pemandu wisata, tempat penjualan souvenir dan makanan, kantor pengelola, mushola, pemandu wisata serta panggung pertunjukan terbuka (Gambar 17 dan 18).

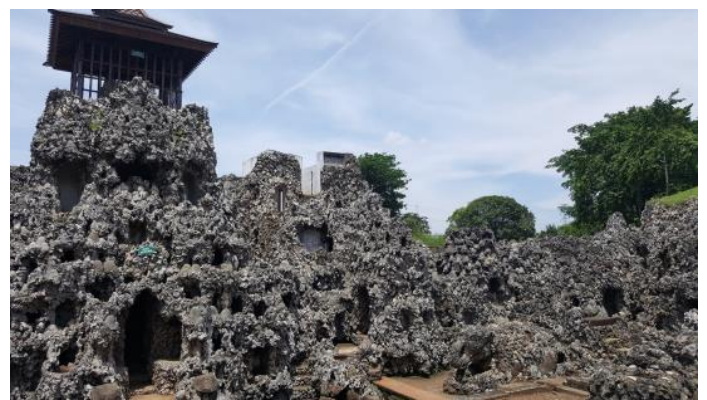

Gambar 17. Taman Air Gua Sunyaragi

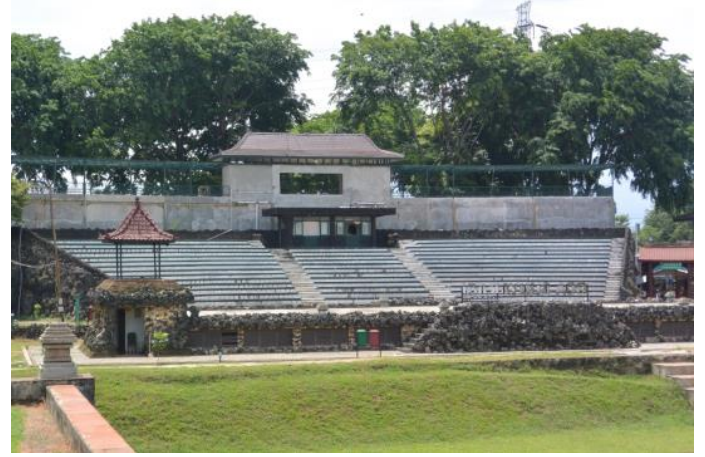

Gambar 18. Panggung Pertunjukan du Gua Sunyaragi

\section{Budaya dan Atraksinya}

Kota Cirebon memiliki potensi kebudayaan yang sangan potensial untuk dikembangkan menjadi komoditas pariwisata yang tinggi sebagai daya tarik Kota Cirebon. Unsur-unsur nilai budaya, adat istiadat dan kesenian menjadi faktor penunjang dalam pembangunan Kota Cirebon. Budaya masyarakat yang cukup religius berbaur dengan tradisi keraton yang bernuansa kerajaan menjadikan ciri khas tersendiri dari Kota Cirebon. Budaya Cirebon berbeda dengan Budaya Sunda ataupun Budaya Jawa, walaupun dibeberpa daerah bisa dijumpai orang yang menggunakan bahasa Sunda atau Jawa; kekhasan segi bahasa ini menjadi daya tarik tersendiri. Selain hal tersebut, Cirebon juga mempunyai atraksi tarian dan wisata budaya. Atraksisi budaya yang masih ada diantaranya terdapat pada Tabel 1.

Tabel 1. Tradisi Keraton dan Masyarakat Cirebon

\begin{tabular}{cll}
\hline No & \multicolumn{1}{c}{ Nama } & \multicolumn{1}{c}{ Pelaksanaan } \\
\hline 1 & Bubur Syura & Setiap 10 Syura \\
2 & Apeman & Setiap 15 Syafar \\
3 & Siraman Panjang & Setiap 8 Mulud \\
4 & Hajat Sebrah, Ukup ke & Setiap 11 Mulud \\
& Astana Agung & \\
5 & Upacara Panjang Jimat & Setiap 12 Mulud \\
6 & Rajaban & Setiap 27 Rajab \\
7 & Nisfu Syaban & Setiap 15 Ruwah \\
8 & Tadarusan & Setiap 1-29 \\
9 & Khataman & ramadhan \\
10 & Hajat Lebaran & Setiap 30 Ramadhan \\
11 & Sekatenan & Setiap 1 Syawal \\
12 & Garebeg Syawal & Setiap 1 Syawal \\
13 & Siraman Gong Sekaten & Setiap 8 Syawal \\
\hline
\end{tabular}

Sumber: Dokumentasi Keraton Cirebon, dalam Nursinggih, 2001 
Selain atraksi budaya juga ada tari-tarian khas Cirebon. Beberapa tarian dan kesenian yang masih menunjukkan khasanah budaya Cirebon diantaranya: Tari Panji dengan topeng warna putih, Tari Tumenggung dengan topeng warna violet, Tari Samba dengan topeng warna kuning, Tari Kelana dengan topeng warna merah, tari Rumiyang dengan topeng warna merah jambu, Tari Tayub, Tari Jaran Lumping, Tari Ronggeng Umbul, Debus, Tarling, seni Gembyung (dokumentasi Keraton Cirebon, dalam Nursinggih, 2001) (Gambar 19 dan 20).

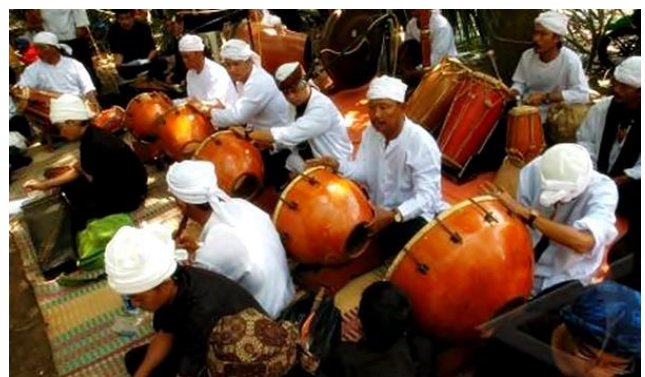

Gambar 19. Aktaksi Kesenian Gembyung Sumber: www.seputar-cirebon.com

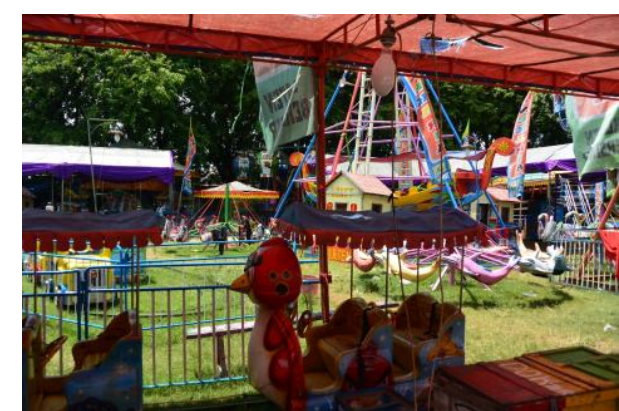

Gambar 20. Aktaksi Sekaten di Sekitar Keraton Kasepuhan

Selain atraksi seni dan budaya, Kota Cirebon juga mempunyai potensi kuliner asli khas Cirebon, sepert Tahu Gejrot, Mie Koclok, Docang, Nasi Jamblang, Nasi Lengko, Empal Gentong dan Manisan khas Cirebon. Cirebon juga terkenal dengan produksi souvenit dan batiknya. Motif Batik khas Cirebon yang paling terkenal adalah motif Mega Mendung (Gambar 21 dan 22).

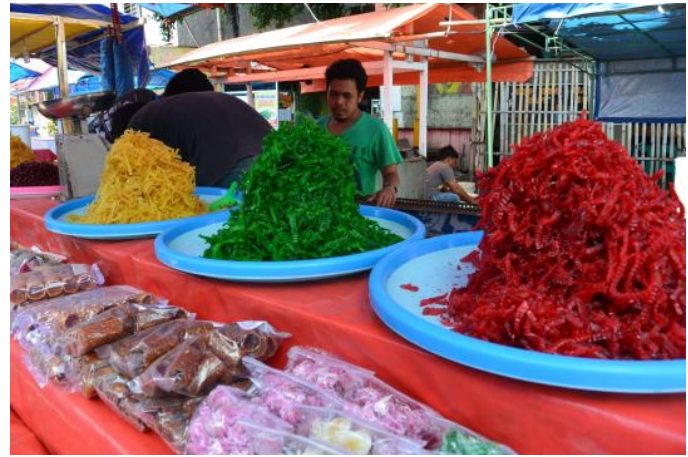

Gambar 21. Manisan Khas Cirebon

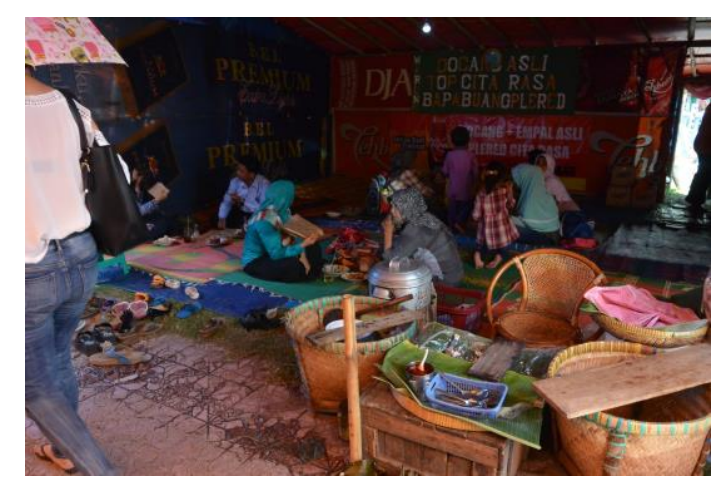

Gambar 22. Empal Genthong Khas Cirebon di Sekaten

Disisi lain sangat disayangkan karena dibeberapa lokasi wisata misalnya Keraton dan Kabuyutan, tradisi masyarakat yang meminta sedekah masih sangat banyak. Sebagai contoh di Keraton Kasepuhan, terutama di museum benda bersejarah dan museum keretanya; disetiap sudut ada bapak-bapak atau remaja yang meminta sedekah dan meletakkannya didekat benda bersejarah tersebut. Hal ini tentu saja mengurangi

kenyamanan wisatawan/pengunjung dalam menikmati wisata mereka, karena tak jarang juga peminta sedekah sedikit memaksa (Gambar 23).

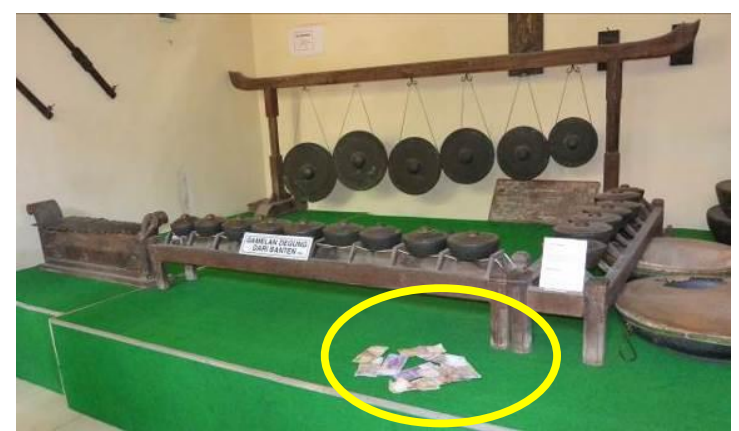

Gambar 23. Tempat meminta sedekah didekat benda bersejarah 


\section{Faktor Internal dan Eksternal Wisata Kota Cirebon}

Hasil penelitian menunjukkan bahwa wilayah Kota Cirebon mempunyai potensi yang besar untuk dikembangkan sebagai kota urban heriatage tourism, dengan melihat adanya bangunan bersejarah, atraksi yang ada serta ragam seni dan budaya. Berdasarkan hal tersebut diatas, analisis SWOT dapat dilakukan untuk menemukan strategi pengembangan wisata tersebut (Nurkukuh, 2015).

1. Strenght (S)

a. Akses yang mudah dijangkau dan kondisi jalan yaang cukup baik.

b. Dekat dengan tempat wisata lain misal Kuningan, Cigugur, dll.

c. Lokasi tempat-tempat bersejarah mayoritas saling berdekatan.

d. Terdapat bangunan bersejarah yang mempunyai arsitektur unik.

e. Beberapa tempat wisata sudah mempunyai sarana dan prasarana yang baik.

f. Sudah ada beberapa atraksi wisata dan fesival budaya.

g. Dibeberapa tempat sudah ada lahan parkir.

h. Beberapa kawasan atau kampung masih mempertahankan ciri-ciri dan identitasnya.

i. Kemudahan mencari akomodasi dan kuliner.

\section{Weakness $(W)$}

a. Dibeberapa tempat, kualitas sarana dan prasarana belum cukup bagus sebagai standar wisata.

b. Dibeberapa tempat wisata, masih ada orang yang meminta-minta kepada wisatawan.

c. Lahan parkir yang ada di beberapa tempat belum optimal terutama untuk mobil dan bis wisata, sehingga parkir kendaraan tidak teratur dan mengambil lahan yang lain.

d. Pengelolaan sampah belum optimal.

e. Kurangnya kualitas dan kuantitas vegetasi yang ada, sehingga pada siang hari terasa panas dan kurang nyaman untuk berjalan kaki.

f. Terdapat PKL yang belum ditata di sekitar lokasi wisata, misalnya di sekitar Kasultanan Kanoman. g. Kurangnya kesadaran dan partisipasi masyarakat terhadap potensi wisata Cirebon.

h. Paket khusus wisata yang coba ditawarkan belum optimal

i. Promosi yang dilakukan belum optimal.

\section{Opportunity $(O)$}

a. Dapat menjadi tempat belajar tentang kebudayaan Islam dan etnis Jawa-Sunda

b. Terdapat wisata kuliner dan wisata edukasi

c. Dapat menjadi lokasi penelitian di bidang ilmu arsitektur, lingkungan, humaniora dan sebagainya

d. adanya peluang investasi di bidang pariwisata

e. akses menuju Kota Cirebon cukup strategis dilalui dari Jakarta, Jawa Tengah maupun Jawa Barat

4. Threat $(T)$

a. Kurangnya minat wisatawan untuk berkunjung

b. Degradasi lingkungan karena masalah lingkungan yang kumuh dan tidak terawat serta sampah

c. Persaingan daya tarik wisata dengan kota-kota lain disekitarnya.

\section{Strategi Pengembangan Heritage} Tourism Kota Cirebon

Beberapa strategi yang bisa dilakukan untuk pengembangan heritage Tourism Kota Cirebon antara lain

1. Strategi Memberdayakan Urban Heritage

a. Memelihara dan mempertahankan originalitas bangunan kuno yang ada supaya keindahan dan vitalitas kawasan terjaga

b. Menghidupkan kembali tradisi atau adat istiadat di Cirebon sebagai atraksi budaya.

c. Meningkatkan sekaligus mewadahi aktivitas budaya dan serta living culture sehingga dapat menambah nilai jual wisata

d. Penetapan Kota Cirebon secara umum dan kawasan kota Cirebon (terutama kawasan kota lama) sebagai kawasan cagar budaya berbentuk living heritage dengan produk hukum (Solikhah, 2015).

e. Perlunya reimagining kota Cirebon yang kontekstual dengan tema kawasan 
heritage namun tetap mendukung fungsi aslinya

2. Strategi Ekonomi

a. Memperbaiki dan meningkatkan fasilitas, infrastruktur serta layanan wisata ke arah professional.

b. Perlu pengembangan dan pembinaan terhadap ekonomi lokal

c. Perlu adanya agenda wisata sehingga wisatawan dapat mengetahui event/acara yang akan dikunjungi.

d. Perlu promosi wisata dan sosialisasi untuk menarik wisatawan.

3. Stategi Partisipasi Masyarakat

a. Adanya peran serta pemerintah, pihak swasta maupun masyarakat untuk pengembangan, pengelolaan serta pemeliharaan warisan cagar budaya.

b. Meningkatkan sense of belonging masyarakat akan potensi wisata Kota Cirebon dari sudut pandang sejarah, budaya, seni dan tradisi masyarakat.

c. Melibatkan masyarakat dalam pemeliharaan dan pemanfaatan urban heritage di Kota Cirebon.

\section{KESIMPULAN}

Berdasarkan hasil penelitian dan pembahasan, maka dapat disimpulkan hal-hal sebagai berikut:

1. Kota Cirebon memiliki potensi wisata yang dapat dijadikan sebagai daya tarik wisata budaya seperti tempat-tempat bersejarah, benda-benda peninggalan sejarah, seni dan budaya serta tradisi dan kehidupan masyarakat.

2. Kurang optimalnya atraksi budaya yang ada karena tidak semua bangunan bersejarah mempunyai atraksi budaya untuk menambah minat wisatawan.

3. Dari analisis SWOT diketahui kekuatan, kelemahan, peluang serta ancaman; sehingga dapat memberikan strategi yang tepat untuk pengembangan urban heritage tourism melalui strategi mempertahankan urban heritage, strategi ekonomi, strategi partisipasi masyarakat.

\section{Daftar Pustaka}

Damanik, Janianton, \& Helmut F. Weber, 2006. Perencanaan Ekowisata: dari Teori ke Aplikasi. Yogyakarta: Penerbit Andi.

Kasultanan Cirebon, 2016. (https://id.wikipedia.org/wiki/Kesultanan _Kacirebonan), diakses 23 Desember 2016.

Keraton-Keraton Di Cirebon, 2014. (https://arifh80.wordpress.com/), diakses 23 Desember 2016.

Masjid Merah Panjunan Cirebon, 2015. (http://www.thearoengbinangproject.com/ masjid-merah-panjunan-cirebon/), diakses 23 Desember 2016.

Nurkukuh, Dwi Kunto, 2015.Strategi Pengembangan. Prosiding. Jakarta: Universitas Tarumanagara.

Nursinggih, Hendro, 2001. Kajian Komponen Penawaran dan Permintaan Wisata sebagai Penunjang Kepariwisataan Budaya Kota Cirebon. Tesis. Semarang: Universitas Diponegoro.

Seni Gembyung, Kesenia Cirebon Yang Masih Lestari, 2015. (http://www.seputarcirebon.com) diakses 23 Desember 2016.

Solikhah, Nafiah, 2015. Kajian Arsitektur Kota Pantai Cirebon dan Strategi Pengembangannya. Prosiding. Jakarta: Universitas Tarumanagara.

Southall, C, \& Peter, 2011. Heritage Tourism. Dalam Robinson, P. Heitmann,S., Dieke, P. Research Theme /for Tourism. CAB International: Library of Congress Cataloging in Publication Data.

Widiyanti, Baiq, 2015. Potensi Pengembangan Wisata Sejarah Budaya di Kawasan Kota Tua Ampenan, Kota Mataram, Provinsi Nusa Tenggara Barat. Prosiding. Jakarta: Universitas Tarumanagara.

Wisata Budaya dan Sejarah di Cirebon, Jawa Barat, 2016. (http://lalerijo.com) diakses 23 Desember 2016. 
Wisata Keraton Di Cirebon, 2016.

(http://www.disparbud.jabarprov.go.id/), diakses 23 Desember 2016. 